\title{
Human Oral Sensitivity to and Taste Modulation by 3-Mercapto-2-Methylpentan-1-ol
}

\author{
Paul M. Wise ${ }^{1}$ (D) $\cdot$ Anne Ledyard ${ }^{1}$ \\ Received: 24 July 2020 / Accepted: 1 February 2022 / Published online: 25 February 2022 \\ (c) The Author(s), under exclusive licence to Springer Science+Business Media, LLC, part of Springer Nature 2022
}

\begin{abstract}
Introduction 3-Mercapto-2-methylpentan-1-ol (3 M) is a key onion flavor (aroma), but past sensory work has focused primarily on ortho-nasal presentation. A series of experiments was conducted to characterize human sensitivity to oral $3 \mathrm{M}$ solutions, then determine how $3 \mathrm{M}$ impacts perception of basic tastes.

Methods Detection thresholds were measured for a food grade, racemic mixture using a forced-choice staircase procedure $(n=19)$. Recognition was measured by presenting a single stimulus per trial (3 M, vanillin, or water), with "onion," "vanilla," or "water" as responses $(n=18)$. Supra-threshold intensity $(n=20)$ was measured for various concentrations using the general labeled magnitude scale (gLMS). Odor-taste interactions were studied using mixtures of $3 \mathrm{M}$ and exemplars of basic tastes. Participants rated the intensity of basic tastes, or both taste and aroma, using the gLMS ( $n$ ranged from 10 to 15 ). All stimuli were in aqueous solution.

Results Participants detected oral $3 \mathrm{M}$ at about $0.90 \mathrm{ppb}$ and recognized $3 \mathrm{M}$ as "onion" at about $5 \mathrm{ppb}$. Supra-threshold intensity increased roughly as a cumulative logistic function of concentration. $3 \mathrm{M}$ enhanced the rated savory intensity of monosodium glutamate, but did not enhance the dominant qualities of exemplars of the other four basic tastes. Under a response-context more favorable to an analytic approach, savory enhancement was reduced but not eliminated. Savory enhancement was eliminated with nose-clips.

Conclusions Oral sensitivity was lower than previous retronasal studies would suggest, but roughly consistent with concentrations in cooked allium varieties. Oral $3 \mathrm{M}$ selectively enhanced savory intensity, an effect likely due to retronasal aroma rather than taste or mouthfeel.
\end{abstract}

Implication $3 \mathrm{M}$ is a promising candidate aroma to enhance or impart a savory flavor.

Keywords Onion aroma $\cdot$ Flavor $\cdot$ Umami enhancement $\cdot$ Savory enhancement $\cdot$ Retronasal sensitivity

\section{Introduction}

\section{3-Mercapto-2-Methylpentan-1-ol: An Important Food Aroma}

The thiol 3-mercapto-2-methylpentan-1-ol (3 M) has a broth-like, slightly sweaty and onion-like aroma (Widder et al. 2000; Granvogl et al. 2004). 3 M was originally isolated from raw onion, but later found to be more concentrated in cooked onion, particularly in some varieties (Widder et al. 2000; Granvogl et al. 2004). Furthermore,

Paul M. Wise

pwise@monell.org

1 Monell Chemical Senses Center, 3500 Market Street, Philadelphia, PA 19104-3308, USA this key onion aroma has proven important in shaping the overall flavor of more complex food matrixes like gravies (Christlbauer and Schieberle 2009, 2011). Since onions are ubiquitous ingredients in world cuisines, $3 \mathrm{M}$ may be among the most important food aromas for humans. Consistent with this idea, humans express a highly sensitive and apparently selective receptor for $3 \mathrm{M}$ (and some close homologues, though with less sensitivity), viz. OR2M3 (Noe et al. 2017). This selectivity is unusual in the highly combinatorial olfactory system (Nara et al. 2011). Thus, sensory properties and flavor contributions of $3 \mathrm{M}$ are of special interest.

\section{Human oral sensitivity to $3 \mathrm{M}$}

Sensory work on $3 \mathrm{M}$ has focused largely on ortho-nasal presentation (Widder et al. 2000; Granvogl et al. 2004; 
Christlbauer and Schieberle 2009, 2011). However, flavor depends more on oral presentation, a key component of which is retronasal olfaction (Delwiche 2004; Shepherd 2006). Since nasal concentration, patterns of sorption on the nasal mucosa, and neural processing can differ between routes of presentation, sensation may also differ (Linforth et al. 2002; Bojanowski and Hummel 2012; Scott et al. 2014; Flaherty and Lim 2017; Hannum et al. 2018; Blankenship et al. 2019; Sanganahalli et al. 2020). Accordingly, one goal was to measure oral sensitivity to $3 \mathrm{M}$ solutions, including detection thresholds (Experiment 1), recognition thresholds (Experiment 2), and supra-threshold intensity vs. concentration (Experiment 3). These sensitivity measures can inform starting concentrations in formulation of foods and provide a foundation for further work on flavor activity. Ortho-nasal sensitivity for $3 \mathrm{M}$ varies among isomers (Lüntzel et al. 2000; Polster and Schieberle 2017), but a food grade, racemic mixture was used for more direct relevance to flavor applications.

\section{The impact of $3 \mathbf{M}$ on basic tastes}

In addition to direct contributions, aromas can modulate the perception of other flavor components, including taste (Roudnitzky et al. 2011; Prescott and Stevenson 2015; Isogai and Wise 2016; Wang et al. 2019; Bertelsen et al. 2020; Fan, Plotto et al. 2021a, b). Taste enhancement is selective (Frank and Byram 1988; Schifferstein and Verlegh 1996; Fan et al. 2021a; Spence 2021). For example, "sweet" smelling aromas selectively enhance sweet taste, and "salty" smelling aromas selectively enhance salty taste (Lawrence et al. 2011; Prescott and Stevenson 2015; Isogai and Wise 2016; Spence 2021). Accordingly, qualitative similarity may facilitate enhancement, though distinct qualitative similarity is not always required (Tieman et al. 2012; Schwieterman et al. 2014).

Regardless, learning is important, and smells can gain the ability to enhance particular tastes after the odor and taste are experienced together (Stevenson et al. 1995; Prescott and Murphy 2009; Gautam and Verhagen 2010), though some more recent work has raised questions about the robustness of these learning effects (Fondberg et al. 2021). Regardless, to the extent learning plays a role in integration of retronasal aroma and taste we might expect $3 \mathrm{M}$, described as brothlike and often experienced in savory dishes, to enhance perceived savory sensation. If so, $3 \mathrm{M}$ would join a relatively small list of volatile flavor compounds shown to affect rated savory taste in laboratory experiments (Rolls 2000; Inoue et al. 2016; Zhou et al. 2021). Though far more studies of odor-taste interactions have focused on sweetness, savory is also a salient and important sensation that contributes to "full, "rich," or "delicious" flavor in the context of many foods (Beauchamp 2009; McCabe and Rolls 2007; Kurihara 2015).

Taste enhancement also depends on the psychophysical task (Green et al. 2012). For example, a strawberry aroma might enhance sweetness under a simple response-context (rating sweetness alone), but not under a more complex response-context in which subjects rate both sweetness and fruitiness (Clark and Lawless 1994; van der Klaauw and Frank 1996). Instructions which focus subjects' attention on particular attributes of stimuli have a similar effect as providing a more complex response-context (van der Klaauw and Frank 1996). Prescott (2012) and others have framed these effects according to attentional strategy, with simple response-contexts or instructions which encourage subjects to judge stimuli as a whole being more likely to result in a synthetic perceptual approach rather than an analytic approach. Enhancement of taste intensity by aroma can still occur under conditions that might be expected to favor a more analytic approach (Isogai and Wise 2016). However, if contributions to rated taste intensity by $3 \mathrm{M}$ are attenuated under a more complex response-context, the result would suggest that aroma and taste sensations are at least partially separable, which in turn would imply that enhancement depends at least in part on cognitive rather than purely peripheral interactions.

In the current experiments, we first determined which of the five basic tastes (sweet, sour, salty, bitter, and savory) $3 \mathrm{M}$ enhanced using a simple response-context favorable to enhancement (Experiment 4). Next, we determined if enhancement seen in Experiment 4 was sensitive to response-context (Experiment 5). Finally, because oral presentation of solutions could involve taste or mouthfeel, we determined if blocking air-flow through nose using noseclips, thereby reducing $3 \mathrm{M}$ concentrations reaching the nasal cavity, would eliminate observed odor-taste interactions (Experiment 6).

\section{Materials and Methods}

\section{Participants}

In total, 35 healthy adults (14 women, 21 men) participated. Ages ranged from 18 to 47 years $($ mean $=33.8$, S.D. $=6.5)$. All were non-smokers with no known food allergies and no sensitivity to monosodium glutamate (by self-report). Most participated in multiple experiments ( 2 in all 6 experiments, 3 in 5, 3 in 4, 8 in 3, 12 in 2, and 7 in 1 experiment). Samples for individual experiments follow: 19 for Experiment 1 (detection thresholds); 18 for Experiment 2 (recognition thresholds); 20 for Experiment 3 (rated intensity); 10 for Experiment 4 (interaction of $3 \mathrm{M}$ with 5 basic tastes); 12 for Experiment 5 (3 M-savory interactions under different 
response-contexts); and 15 for Experiment 6 (3 M-savory interactions with and without nose-clips).

All were healthy and free of food allergies or sensitivity to MSG by self-report. None were smokers. Participants were employees of the Monell Chemical Senses Center, students from local universities, or others from the surrounding community. Most had previous experience in sensory tests of taste and smell. All provided written informed consent prior to any experimental procedures. Procedures were approved by an institutional review board at the University of Pennsylvania (protocol \#826,403), and the work was conducted according to the principles of the Declaration of Helsinki.

\section{Materials}

Compounds were FCC or food grade: (1) sucrose (CAS\# 57-50-1, MP Biomedicals LLC), (2) monosodium L-glutamate (MSG; CAS\# 6106-04-3; $\geq 98.5 \%$; Spectrum Chemical MFG Corp), (3) sodium chloride ( $\mathrm{NaCl}$; CAS\# 7647-14$5 ; \geq 99 \%$ Fisher Chemical), (4) quinine monohydrochloride dihydrate (QHCl; CAS\# 6119-47-7; $\geq 95 \%$, Sigma-Aldrich); (5) citric acid (CAS\#77-92-9, $\geq 99 \%$ Sigma-Aldrich), (6) vanillin (or "vanilla;" CAS\#121-33-5; $\geq 97 \%$; SigmaAldrich), and (7) 3-mercapto-2-methylpentan-1-ol (3 M; CAS\# 227,456-27-1; $\geq 98 \%$, racemic mixture; Penta Manufacturing). For $3 \mathrm{M}$, the exact ratios of isomers in the racemic mixture were not specified by the manufacturer. For completeness of identification, the Penta product code for $3 \mathrm{M}$ was $13-15,675$, lot number 123922 . At the concentrations used, materials were miscible in distilled, Millipore®filtered, deionized water (solutions did not visibly separate). Solutions were stored in amber bottles under refrigeration, and were re-made after 4 days.

Solutions were presented in 2-ml microcentrifuge tubes (Eppendorf). Tubes were sealed with attached snap-caps to prevent ortho-nasal detection and warmed to room temperature before use. To sample, participants first exhaled naturally, opened the tube, took the contents into the mouth, then closed the mouth and discarded the tube before breathing again. Participants rolled the sample around in the mouth for several seconds while breathing naturally before making judgments. Subjects were instructed not to swallow samples (sip-and-spit procedure), rinsing at least twice with Millipore $^{\mathrm{TM}}$ filtered water after each sample. These general sampling procedures were used for all six experiments.

\section{Procedures}

Participants were instructed not to eat, drink anything except water, or use oral hygiene products for at least $1 \mathrm{~h}$ before sessions, and to avoid strongly-scented personal products. Participants began all sessions by rinsing the mouth four times with Millipore ${ }^{\mathrm{TM}}$ filtered water to produce a more stable starting condition. Participants were tested in dedicated sensory testing rooms $\left(\sim 21{ }^{\circ} \mathrm{C}\right.$, under fluorescent lighting). Participants were tested individually, with only an experimenter and the participant present in the room. All testing was completed before the beginning of the COVID19 pandemic.

\section{Experiment 1 (Detection)}

A modified staircase procedure was used (Wetherill and Levitt 1965; Wise and Breslin 2013). The task was twoalternative, forced-choice (water blank versus a dilution of $3 \mathrm{M}$, in random order). Concentration of $3 \mathrm{M}$ varied according to a 2-down, 1 -up rule for five reversals. If concentration drifted more than three dilution steps from the last reversal, the reversal count began again to make chance-reversals less influential. Concentration ranged from $0.0017 \mathrm{ppb}$ by mass to $100.0 \mathrm{ppb}$ in 11 , threefold dilution steps (selected based on preliminary work). The geometric mean of the concentrations associated with the last four reversals served as threshold estimate. Participants completed two sessions, separated by 1 to 7 days. Two threshold measurements were collected each session, with a break of about $10 \mathrm{~min}$ in between. For the first run, concentration started in the middle of the range and at the previously measured threshold thereafter. Replicates within a session were averaged. Re-test reliability was assessed using the intra-class correlation (ICC). Data were summarized across subjects using the geometric mean, since the distribution was positively skewed.

\section{Experiment 2 (Recognition)}

Participants (18 of the 19 who participated in Experiment 1) sampled one solution per trial, with the following responses: "onion," "vanilla," or "water." After making the judgment, participants expectorated the sample and rinsed at least twice with Millipore ${ }^{\mathrm{TM}}$ filtered water to begin a 45 -s inter-trial interval. Sessions were composed of blocks of 11 trials (in random order). Seven were a threefold dilution series of $3 \mathrm{M}$ tailored to individuals. One dilution fell at least threefold below the average of the four previously measured detection thresholds for the participant, and at least five concentrations fell above threshold. Two more trials were water blanks, and the other two were $0.12 \mathrm{mM}$ and $0.35 \mathrm{mM}$ vanillin. In preliminary work, most people recognized the higher concentration of vanillin, but some people found it difficult to recognize the lower concentration. Blanks and vanillin were included to prevent $100 \%$ correct recognition by always responding "onion." After a practice block, subjects completed two blocks, separated by a break of about $10 \mathrm{~min}$, in each of two experimental sessions (four blocks in total for analysis). Between one and 5 days separated sessions. 
Data for each participant were pooled across blocks to plot proportion of "onion" responses versus $3 \mathrm{M}$ concentration. Resulting plots were fit (via least squares regression) with cumulative logistic functions using the robust Solver ${ }^{\circledR}$ tool in Microsoft Excel (Version 14.0.7212.5000)(Gadagkar and Call 2015):

$\mathrm{p}$ (“onion" $)_{\text {pred }}=\mathrm{p}(\text { ("onion” })_{\min }+\left[\frac{\left.[\mathrm{p} \text { (onion })_{\max }-\mathrm{p}(\text { onion })_{\min }\right]}{1+\left(\frac{\mathrm{EC}_{50}}{\mathrm{C}}\right)^{\mathrm{S}}}\right]$,

where $p$ ("onion") $)_{\text {pred }}$ represents predicted probability of responding "onion" at concentration $\mathrm{C}, \mathrm{p}$ ("onion") $)_{\min }$ represents the lower asymptote, $p$ ("onion") ${ }_{\max }$ represents the upper asymptote, $\mathrm{EC}_{50}$ represents the point of inflection ("threshold"), and S represents slope. In one set of fits, the upper asymptote was fixed at 1.0, whereas the lower asymptote, slope, and point of inflection were free parameters. In another set of fits the lower asymptote was also fixed, at the proportion of water blanks the participant in question called "onion." Recognition thresholds $\left(\mathrm{EC}_{50}\right)$ estimates from the two analyses agreed well (Pearson's $r=0.99$ ), so only recognition thresholds from the second method (fixed lower asymptote) are reported. The distribution was less obviously skewed than that for detection, but the geometric mean was used to summarize recognition thresholds across subjects for consistency.

\section{Experiment 3 (Supra-threshold Intensity)}

Participants used the general labeled magnitude scale (gLMS) to rate the intensity of "onion aroma," demonstrated using $300 \mathrm{ppb} 3 \mathrm{M}$ presented orally. The gLMS is a line scale with verbal descriptors ("no sensation," "barely detectable," "weak," "moderate," "strong," "very strong," and "strongest imaginable sensation of any kind") spaced to provide approximately ratio-level measurement (Green et al. 1996; Bartoshuk et al. 2004). Participants were instructed following published procedures, including ratings of remembered or imagined sensations (Green 2002; Bartoshuk et al. 2004). Participants also demonstrated understanding by rating the intensity of three concentrations of sucrose.

Each trial, a participant sampled one solution, rated intensity, expectorated the sample, and rinsed twice to begin a 45 -s inter-trial interval. Stimuli included a water blank plus six concentrations of $3 \mathrm{M}$, selected in preliminary work to span a wide range of perceived intensities for most people: $3.7,11.1,33.3,100,300$, and $900 \mathrm{ppb}$. A water blank was also included. In each of two sessions, subjects rated all stimuli twice each in blocked, random order. Between 1 and 6 days separated the two sessions.
For analysis, replicate ratings of perceived intensity (within subjects) were averaged using the arithmetic mean, then averaged across subjects using the geometric mean since gLMS ratings tend to be distributed in an approximately log-normal fashion across subjects (Green et al. 1996). A cumulative logistic function was fit to plots of intensity vs. concentration using methods comparable to those described in "Experiment 2 (Recognition)," above.

\section{Experiment 4 (Effect on Basic Tastes)}

An initial experiment was conducted to determine which basic taste qualities (sweet, sour, salty, bitter, or savory) are likely to be affected by $3 \mathrm{M}$. Stimuli included five matrixes, one to represent each basic taste quality: $200 \mathrm{mM}$ sucrose for sweet, $1.5 \mathrm{mM}$ citric acid for sour, $35 \mathrm{mM} \mathrm{NaCl}$ for salty, $0.04 \mathrm{mM}$ $\mathrm{QHCl}$ for bitter, and $18 \mathrm{mM}$ MSG for savory. Preliminary work suggested that these concentrations were comparable in perceived intensity (between "weak" and "moderate" on the gLMS). Each tastant was crossed with three added aroma conditions: no aroma (comparison), 300 ppb $3 \mathrm{M}$, and $1.06 \mathrm{mM}$ vanillin. Vanillin was selected as a positive control, since it frequently enhances rated sweetness, and the concentration was selected as comparable to that of $300 \mathrm{ppb}$ $3 \mathrm{M}$. To encourage a synthetic approach, participants rated only the dominant taste quality for various stimuli.

Subjects evaluated each matrix in separate blocks of six trials: 1 taste $\times 3$ aroma conditions $\times 2$ replicates, in blocked random order. Within a session, the five tastes were evaluated in random order. Subjects completed two experimental sessions, for a total of four trials per condition (two replicates in each of two sessions). During training, taste quality was demonstrated using the same five tastants (though, for MSG, subjects were told that many people find MSG to be slightly salty as well as savory). In other respects, procedures were similar to those for Experiment 3.

\section{Experiment 5 (Effect on Savory and Interaction With Response-Context)}

A more detailed experiment, focusing primarily on interactions between oral $3 \mathrm{M}$ and the savoriness of MSG, was conducted to follow-up on the findings of Experiment 4. Stimuli included two matrixes: (1) two levels of MSG (0 and $18 \mathrm{mM})$ crossed with five levels of $3 \mathrm{M}(0,33,100$, 300 , and $900 \mathrm{ppb} 3 \mathrm{M}$ ) and (2) to confirm selective interaction between $3 \mathrm{M}$ and savory taste, two levels of sucrose (0 and $200 \mathrm{mM})$ crossed with five levels of $3 \mathrm{M}(0,33,100$, 300 , and $900 \mathrm{ppb} 3 \mathrm{M}$ ). In addition, there were two rating conditions, administered in separate blocks of trials within experimental sessions. In one rating condition (only taste), participants were instructed to rate the intensity of the five 
basic tastes (sweet, sour, salty, bitter, and savory). In the other rating condition (taste plus aroma), participants were instructed to rate the intensity of the five basic tastes and also rate the intensity of "onion aroma." Both responsecontexts might be more likely to encourage an analytic approach than just rating a single basic taste, though past work suggests that the option to rate aroma as well as taste may be particularly important (Clark and Lawless 1994; Green et al. 2012).

Participants completed two sessions. In each session, they evaluated each stimulus-matrix twice: 20 trials for the sweet matrix and 20 trials for the savory matrix (within blocks: all 10 stimuli in random order, then again in random order). A break of about 10 min separated the blocks within sessions. Order of the blocks (sweet first vs. savory first) was counterbalanced across sessions. Order of rating condition was counterbalanced across subjects. Otherwise, procedures were similar to those used in Experiments 3 and 4 .

\section{Experiment 6 (Effect on Savory, With and Without Nose-Clips)}

Because oral $3 \mathrm{M}$ could contribute taste or mouthfeel, $3 \mathrm{M}$-savory interactions were assessed both with the nostrils open and with the nostrils closed using foam-padded spirometry nose-clips (ndd Medical Technologies, Andover MA, USA). Closing the nostrils greatly reduces or eliminates airflow through the nasal cavity, thereby reducing concentrations of volatiles reaching the nose from the mouth.

The single stimulus-matrix consisted of two concentrations of MSG ( 0 and $18 \mathrm{mM}$ ) crossed with five concentrations of $3 \mathrm{M}(0,33,100,300$, and 900 ppb $3 \mathrm{M})$. In a single session, subjects completed two blocks of 20 trials (all 10 stimuli in random order, then again in random order), separated by a break of about $10 \mathrm{~min}$. Nose-clips were used in one block of 20 trials, but not in the other (order counterbalanced across subjects). Subjects rated just the five basic tastes to encourage a more synthetic approach. When using clips, participants put them on before opening a sample tube, and clips remained in place until participants completed judgments, expectorated the sample, and rinsed to begin a 45-s inter-trial interval. Otherwise procedures were similar to those of Experiments 3, 4, and 5.

\section{Data analysis}

Descriptive statistics were calculated using Microsoft Excel (Version 14.0.7212.5000). Inferential statistics were calculated using Statistica (Dell; Version 13). Effects of oral $3 \mathrm{M}$ on taste (Experiments 4-6) were assessed using ANOVA models. Post hoc tests to follow-up significant ANOVA results included simpler ANOVAs and two-tailed Dunnett tests (Dunnett 1955) to compare solutions with added aroma to solutions without added aroma.

\section{Results}

\section{Experiment 1 (Detection Thresholds)}

Geometric mean detection threshold was $0.90 \mathrm{ppb}, 95 \% \mathrm{CI}$ [0.34, 2.37]. Re-test reliability between replicate measurements within each session was reasonable: ICC for session $1=0.81, p<0.001$; ICC for session $2=0.93, p<0.001$. Re-test reliability between experimental sessions (i.e., between average threshold for session 1 versus average threshold for session 2) was also reasonable: $\mathrm{ICC}=0.85$, $p<0.001$. Individual thresholds ranged from 0.075 to $44.43 \mathrm{ppb}$ (588-fold range), with an apparent positive skew (Fig. 1).

\section{Experiment 2 (Recognition Thresholds)}

Geometric mean recognition threshold was $5.18 \mathrm{ppb}$, 95\% CI [1.50, 17.89]. Individual recognition thresholds ranged from 0.15 to $173.21 \mathrm{ppb}$ (1133-fold range). Relative to the distribution of detection thresholds, recognition thresholds appeared to have a higher proportion of scores toward the upper end of the distribution (Fig. 2). Response proportions by stimulus for recognition trials appear in Table 1.

Geometric mean ratio of recognition threshold to detection threshold was $5.62,95 \%$ CI [2.49, 12.68], so subjects recognized $3 \mathrm{M}$ as "onion" at concentrations about six-fold higher than required to discriminate $3 \mathrm{M}$ from plain water

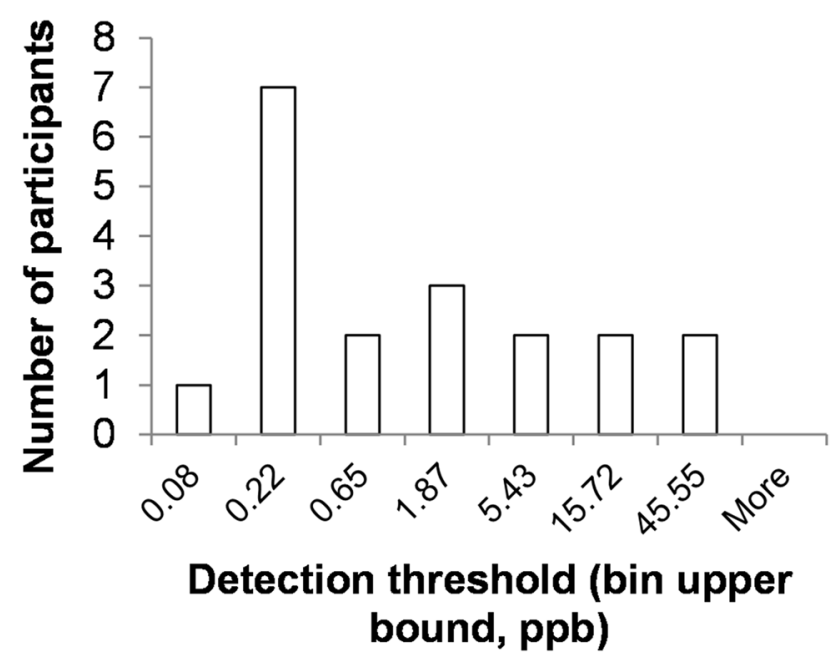

Fig. 1 Histogram of detection (absolute) thresholds for 3-mercapto2-methylpentan-1-ol $(n=19)$ 


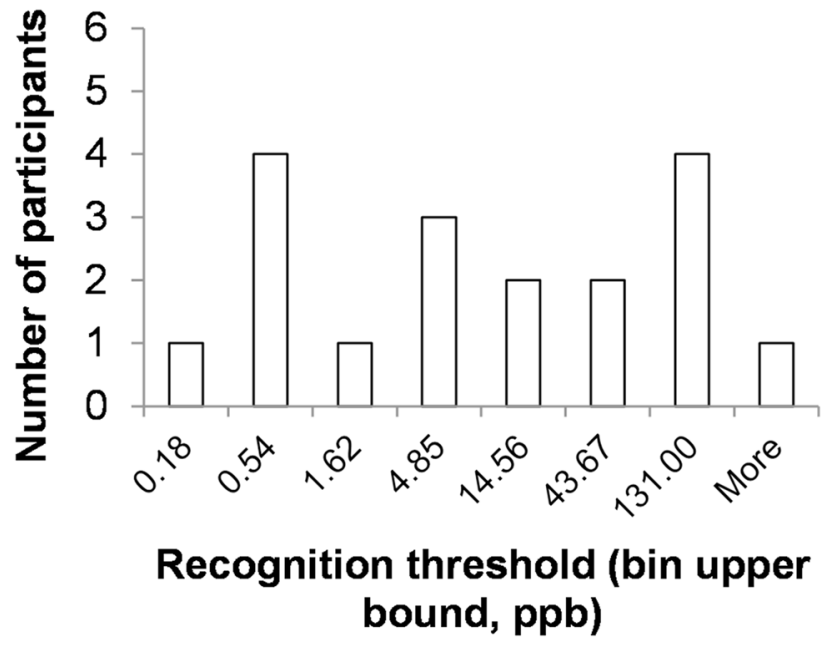

Fig. 2 Histogram of recognition thresholds for 3-mercapto-2-methylpentan-1-ol $(n=18)$

(Fig. 3). Recognition thresholds were correlated with detection thresholds, $r(16)=0.76, p<0.001$.

\section{Experiment 3 (Supra-threshold Intensity)}

Rated onion aroma intensity was submitted to a one-way (concentration) ANOVA. Intensity increased with $3 \mathrm{M}$ concentration, $F(6,114)=35.66, p<0.001$, an expected dose-response relationship (Fig. 4). The average (across concentrations) ICC between sessions was 0.51 (S.D. $=0.21$ ). Ratings for the water blank were close to "barely detectable," though significantly greater than zero according to a one-group $t$-test, $t(19)=5.17, p<0.0001$. According to a post hoc (Dunnett) test, all concentrations of $3 \mathrm{M}$ were rated as significantly different (more intense) than water.

A three-parameter, cumulative logistic fit (lower asymptote set to the rated intensity for the blank) predicted a maximum rated intensity of 43.0 (between "strong" and "very strong"), with the point of inflection (half-maximum intensity) at $1165 \mathrm{ppb}$ (Fig. 4).

Table 1 Mean $( \pm$ SEM) response proportions, averaged across stimulus concentration

\begin{tabular}{llll}
\hline & \multicolumn{2}{l}{ Stimulus } & \\
\cline { 2 - 4 } Response & Vanillin & $3 \mathrm{M}$ & Blank \\
\hline "Vanilla" & $0.88 \pm 0.04$ & $0.09 \pm 0.02$ & $0.21 \pm 0.04$ \\
"Onion" & $0.04 \pm 0.02$ & $0.55 \pm 0.04$ & $0.16 \pm 0.05$ \\
"Water" & $0.08 \pm 0.03$ & $0.36 \pm 0.04$ & $0.63 \pm 0.06$ \\
\hline
\end{tabular}

Total number of trials per subject: 32 for $3 \mathrm{M}, 8$ for vanillin, 8 for the water blank

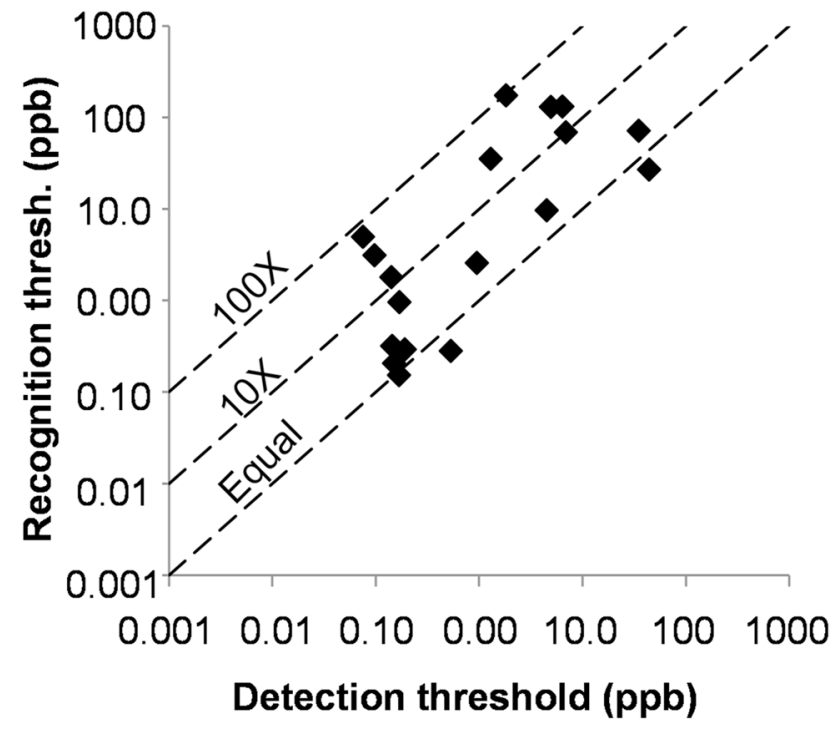

Fig. 3 Scatter plot of recognition threshold (y-axis) for 3-mercapto2-methylpentan-1-ol versus detection threshold ( $x$-axis) for the 18 participants who contributed both detection and recognition data. Dashed lines mark regions of graph where detection is equal to recognition, tenfold higher than detection, and 100-fold higher than detection

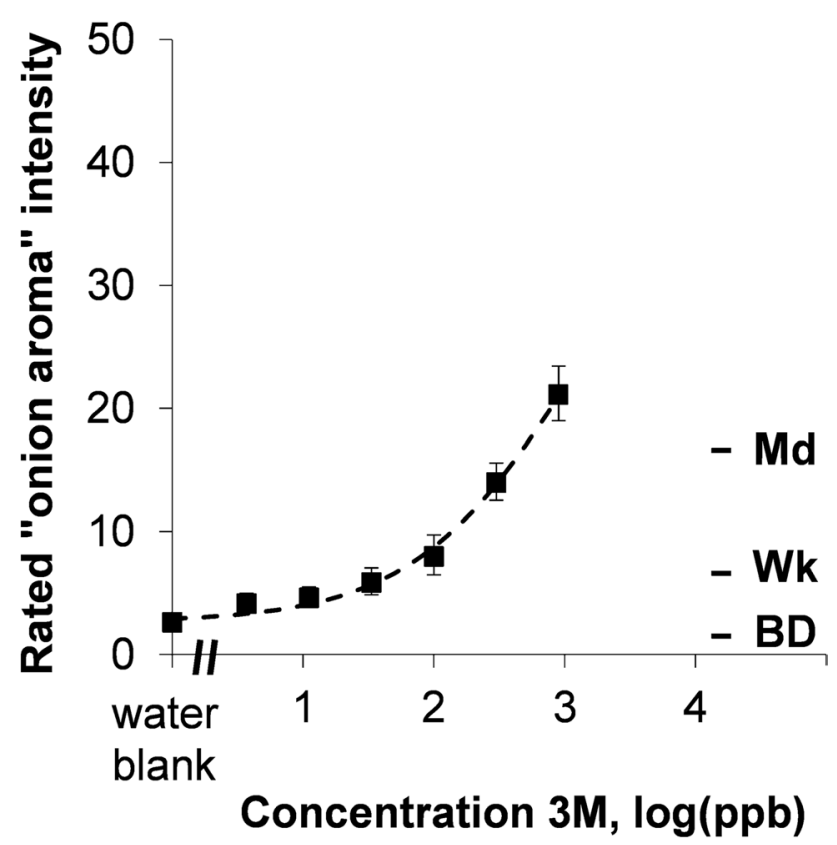

Fig. 4 Geometric mean rated onion aroma intensity ( \pm S.E.M., $Y$-axis) versus concentration of 3-mercapto-2-methylpentan-1-ol ( $3 \mathrm{M}, X$-axis) in parts per billion $(n=20) . \mathrm{gLMS}=$ general labeled magnitude scale. Ticks to the right of the graph illustrate the positions of three intensity descriptors: BD, "barely detectable"; Wk, "weak"; and Md, "moderate" 


\section{Experiment 4 (Effect on Basic Tastes)}

Under a very simple response-context, vanillin selectively enhanced the sweetness of sucrose, and $3 \mathrm{M}$ selectively enhanced the savory intensity of MSG. Thus, 3 M-savory interactions seemed most promising for further investigation.

A 2-way (session $\times$ added aroma) ANOVA on the rated sweetness of sucrose yielded a statically significant effect of Added aroma, $F(2,18)=4.69, p<0.03$. According to a Dunnett test, sweetness was significantly different (about $55 \%$ greater; Fig. 5) with vanillin compared to no aroma, but $3 \mathrm{M}$ was not different from no aroma. The effects of session and the interaction were not significant $(p=0.17$ and 0.40 , respectively).

A parallel ANOVA on rated savory intensity of MSG yielded a significant main effect of added aroma, $F(2,18)=6.27, p<0.01$. According to post hoc analysis, savory intensity with $3 \mathrm{M}$ was significantly different (about $76 \%$ greater; Fig. 5) from no aroma, but vanillin was not different from no aroma. The effects of session and the interaction did not reach significance $(p=0.42$ and 0.24 , respectively).

For rated sourness of citric acid, saltiness of $\mathrm{NaCl}$, and bitterness of $\mathrm{QHCl}$, neither main effects nor interactions reached significance ( $p$-values ranged from 0.14 to 0.61 ).
Across the experiment, average ICC (between sessions) was 0.64 (S.D. $=0.26)$.

\section{Experiment 5 (3 M Interactions with Savory)}

In a more focused investigation of interactions between MSG and multiple concentrations of $3 \mathrm{M}$ (retaining sucrose as a second tastant for comparison), participants again rated mixtures of MSG and $3 \mathrm{M}$ as more savory than MSG without $3 \mathrm{M}$. Participants also rated $3 \mathrm{M}$ without MSG as savory. Under a response-context less favorable to an analytic approach (also rating "onion aroma" each trial), savory ratings of $3 \mathrm{M}$ were attenuated. Ratings of "onion aroma" were not affected by tastants.

\section{MSG Mixed with $3 \mathrm{M}$}

Sweetness, sourness, and bitterness for mixtures of MSG and $3 \mathrm{M}$ were around "barely detectable" or lower, and comparable to those for water blanks. Thus, only ratings of saltiness and savory were analyzed further.

Salty ratings were submitted to a 3-way ANOVA: MSG $(0$ vs. $18 \mathrm{mM}) \times 3 \mathrm{M}(0,33,100,300$, and $900 \mathrm{ppb}) \times$ scaling condition (rating only the five basic tastes each trial vs. also rating onion aroma). The effect of MSG reached
Fig. 5 Geometric mean rated intensity ( \pm S.E.M., $Y$-axis) of the dominant taste quality of exemplars of the five basic tastes with no aroma added (comparison condition), with 300 ppb 3-mercapto-2-methylpentan-1-ol (3 M) added, or with $1.06 \mathrm{mM}$ vanillin added $(n=10)$. Ticks to the right of the graph illustrate the positions of three intensity descriptors: $\mathrm{BD}$, "barely detectable"; Wk, "weak"; and Md, "moderate." An asterisk (*) indicates ratings significantly different from the corresponding no aroma condition according to a 2-tailed Dunnet test

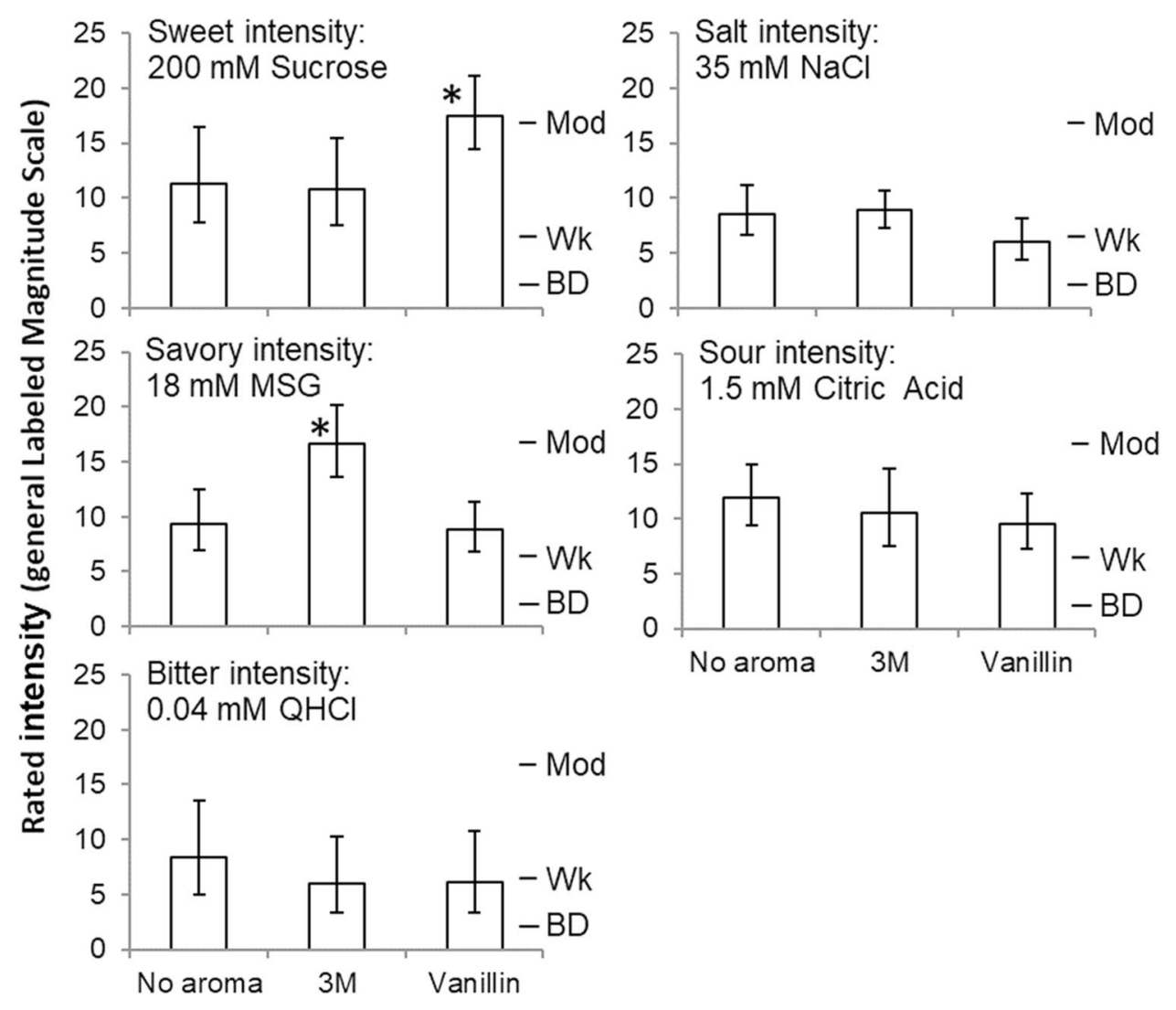


Fig. 6 Geometric mean rated intensity ( \pm S.E.M., $Y$-axis) of various sensations for a stimulus-matrix of MSG and 3-mercapto-2-methylpentan1 -ol (3 M; $n=12)$. In some conditions subjects rated just the five basic tastes each trial, whereas in other conditions subjects rated the intensity of "onion aroma." An asterisk (*) indicates ratings significantly different from the corresponding 0 ppb $3 \mathrm{M}$ condition according to a 2-tailed Dunnet test (based on one-way ANOVAs reported in Table 2) w/out rating aroma

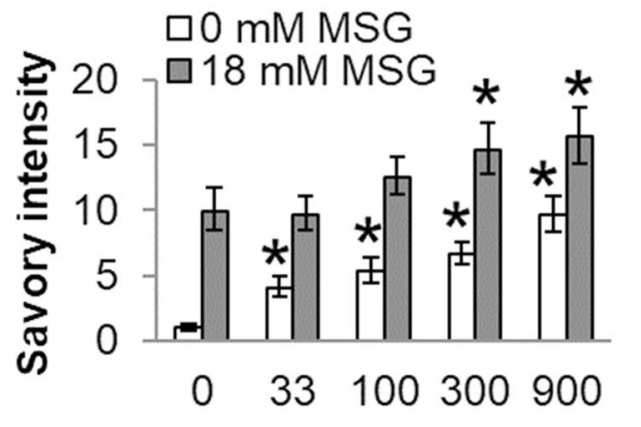

w/out rating aroma

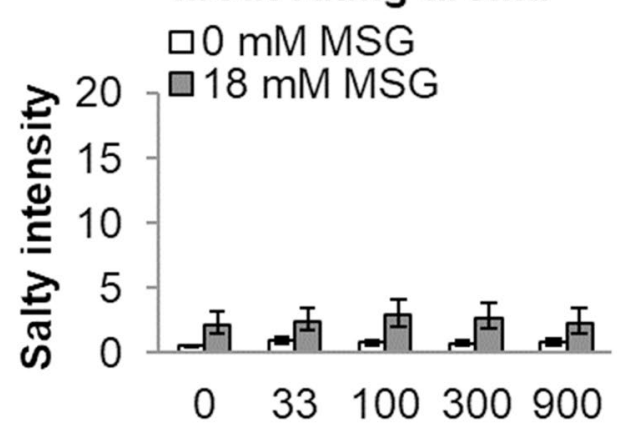

when rating aroma

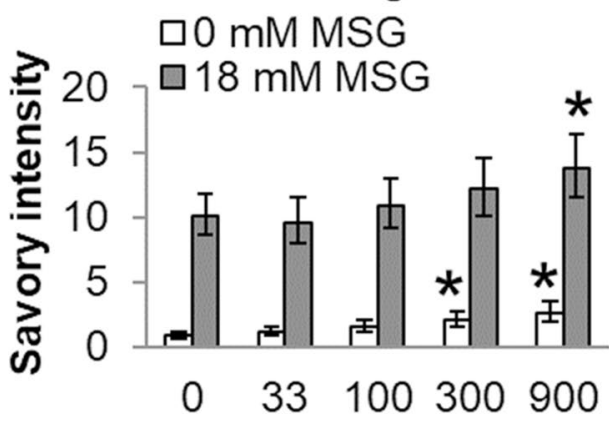

when rating aroma

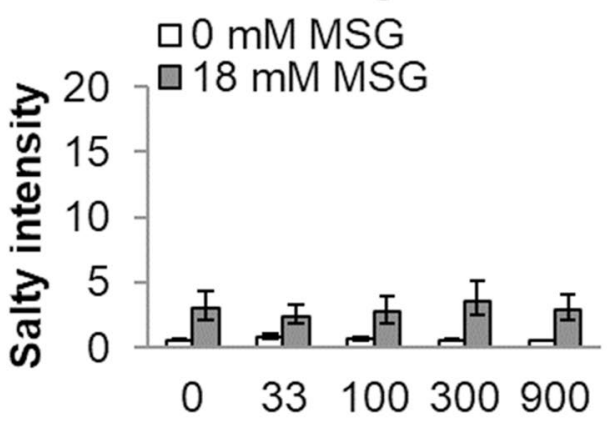

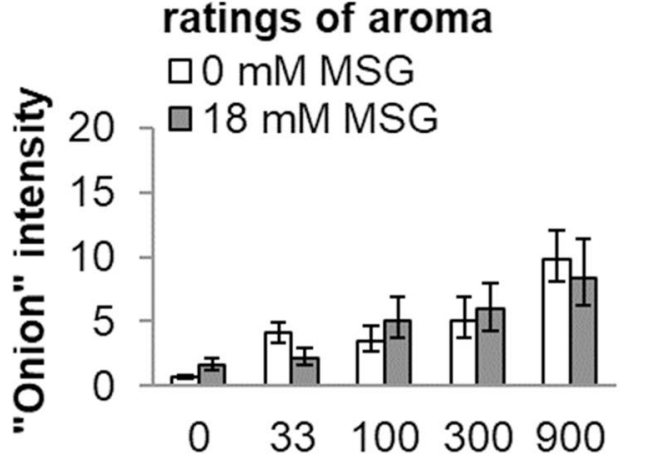

Concentration $3 \mathrm{M}(\mathrm{ppb})$

significance, $F(1,11)=21.76, p<0.001$. Samples with $18 \mathrm{mM}$ MSG were rated as very weakly salty, whereas samples without MSG were not (Fig. 6). The other main effects and all interactions failed to reach significance ( $p$-values from 0.12 to 0.98 ). Accordingly, $3 \mathrm{M}$ had no measureable effect on the rated saltiness of MSG.
Table 2 One-way ANOVA results for the effect of $3 \mathrm{M}$ concentration on savory ratings, Experiment 5

\begin{tabular}{lllll}
\hline Stimulus-matrix & Rating condition & $\begin{array}{l}\text { Tastant concen- } \\
\text { tration }\end{array}$ & $\begin{array}{l}F \text {-value [degrees of } \\
\text { freedom }(4,44)\end{array}$ & $p$-value \\
\hline MSG-3 M & Taste & $0 \mathrm{mM}$ & 24.20 & $<0.00001$ \\
MSG-3 M & Taste & $18 \mathrm{mM}$ & 7.99 & 0.00006 \\
MSG-3 M & Taste+ "onion” & $0 \mathrm{mM}$ & 4.51 & 0.0039 \\
MSG-3 M & Taste+ "onion" & $18 \mathrm{mM}$ & 4.21 & 0.0057 \\
Sucrose-3 M & Taste & $0 \mathrm{mM}$ & 62.97 & $<0.00001$ \\
Sucrose-3 M & Taste & $200 \mathrm{mM}$ & 10.70 & $<0.00001$ \\
Sucrose-3 M & Taste+ "onion" & $0 \mathrm{mM}$ & 9.23 & 0.00002 \\
Sucrose-3 M & Taste+"onion" & $200 \mathrm{mM}$ & 2.95 & 0.030 \\
\hline
\end{tabular}


Savory ratings were submitted to a parallel, 3-way ANOVA. The effect of MSG reached significance, $F(1$, $11)=72.84, p<0.0001$. Samples with MSG were rated as savory, whereas samples without MSG were rated as having little or no savory taste (Fig. 6). The effect of $3 \mathrm{M}$ also reached significance, $F(4,44)=28.05, p<0.000001$. Savory intensity increased with concentration of $3 \mathrm{M}$. Oneway (3 $\mathrm{M}$ concentration) ANOVAs were significant for all four combinations of scaling condition and MSG concentration (Table 2). Furthermore, there was a significant MSG $\times 3$ M interaction, $F(4,44)=13.10, p<0.000001$ : not only did savory intensity increase with $3 \mathrm{M}$ concentration even when no MSG was present, savory intensity actually increased more sharply with $3 \mathrm{M}$ concentration for $0 \mathrm{mM}$ MSG (Fig. 6).

Scaling condition was significant, $F(1,11)=13.70$, $p<0.01$. Savory ratings made while also rating onion aroma were lower than ratings made while only rating taste. Furthermore, there was a significant scaling condition by $3 \mathrm{M}$ interaction, $F(4,44)=3.52, p<0.05$. In a follow-up ANOVA on only samples with aroma, the effect of scaling condition was significant, $F(1,11)=17.28, p<0.002$, but was not in an ANOVA on only samples without added aroma $(p=0.71)$. Accordingly, scaling condition only mattered for samples with added aroma. Returning to the 3-way ANOVA, there was a significant scaling condition by MSG interaction, $F(1,11)=20.86, p<0.001$. In a follow-up ANOVA on only samples with MSG, the effect of scaling condition was not significant $(p=0.48)$, but was significant in an ANOVA on only samples without MSG, $F(1,11)=20.87, p<0.001$. Thus, scaling condition only mattered (or at least mattered more) for samples without MSG. The 3-way interaction was not significant $(p=0.10)$.

Ratings of onion aroma were submitted to a 2-way ANOVA: MSG ( 0 or $18 \mathrm{mM}$ ) by $3 \mathrm{M}$ concentration $(0,33$, $100,300$, and $500 \mathrm{ppb})$. The effect of $3 \mathrm{M}$ reached significance, $F(4,44)=25.09, p<0.00001$. Onion aroma increased with $3 \mathrm{M}$ concentration as expected. Other effects were not significant ( $p=0.74$ and 0.13 , respectively). Thus, MSG had little or no impact on onion aroma.

\section{Sucrose Mixed with $3 \mathrm{M}$}

Saltiness, sourness, and bitterness for mixtures of sucrose and $3 \mathrm{M}$ were around "barely detectable" or lower, comparable to water blanks. Thus, only ratings of sweet and savory were analyzed further.

Sweetness ratings were submitted to a 3-way ANOVA: sucrose $(0$ vs. $200 \mathrm{mM}) \times 3 \mathrm{M}(0,33,100,300$, and $900 \mathrm{ppb}) \times$ scaling condition. The effect of sucrose was significant, $F(11,44)=119.10, p<0.000001$. Samples with sucrose were rated as sweeter than samples without. No other effects reached significance ( $p$-values between 0.10 and 0.79 ). Thus, $3 \mathrm{M}$ did not affect sweetness.

Savory ratings were submitted to a parallel 3-way ANOVA. The effect of sucrose failed to reach significance $(p=0.20)$. Nominally, savory ratings were lower with sucrose than without. The effect of $3 \mathrm{M}$ reached significance, $F(4,44)=41.93, p<0.000001$. Savory intensity increased with $3 \mathrm{M}$ concentration (Fig. 7). One-way (3 M concentration) ANOVAs were significant for all four combinations of rating condition and sucrose concentration (Table 2). The interaction between Sucrose concentration and $3 \mathrm{M}$ reached significance, $F(4,44)=5.49, p<0.01$. This interaction seemed to depend largely on samples without $3 \mathrm{M}$, which had little or no savory intensity (Fig. 7). In a followup ANOVA on only samples with $3 \mathrm{M}$, the sucrose concentration $\times 3 \mathrm{M}$ interaction was not significant $(p=0.51)$. Regardless, 3 M seemed to impart a "savory" note even to sucrose solutions. Unlike MSG, sucrose did not seem to cooperate with $3 \mathrm{M}$ to increase savory (if anything, sucrose suppressed savory).

The effect of scaling condition also reached significance, $F(1,11)=11.04, p<0.01$. Savory ratings made without rating onion aroma were higher compared to when participants also rated aroma. Furthermore, there was a significant interaction between scaling condition and $3 \mathrm{M}$, $\mathrm{F}(4,44)=7.59, p<0.001$. In a follow-up ANOVA on only samples with aroma, scaling condition reached significance, $F(1,11)=13.57, p<0.01)$, but did not in an ANOVA on only samples without added aroma $(p=0.74)$. Thus, scaling condition only mattered when samples had $3 \mathrm{M}$. In the overall ANOVA, the scaling condition by sucrose interaction $(p=0.10)$ and the 3 -way interaction $(p=0.45)$ failed to reach significance. Taken together, the results suggest that ratings of savory intensity of $3 \mathrm{M}$ were sensitive to response-context.

Ratings of onion aroma were submitted to a 2-way ANOVA: Sucrose concentration ( 0 or $200 \mathrm{mM}$ ) by $3 \mathrm{M}$ concentration $(0,33,100,300$, and $900 \mathrm{ppb})$. The effect of $3 \mathrm{M}$ reached significance, $F(4,44)=27.92, p<0.00001$. Onion aroma increased with $3 \mathrm{M}$ concentration. Other effects were not significant ( $p=0.09$ and 0.11 ). Accordingly, sucrose had little or no impact on onion aroma (nominally, ratings were lower with added sucrose).

\section{Experiment 6 (Effect on Savory, With and Without Nose-Clips)}

Participants rated MSG mixed with $3 \mathrm{M}$ as more savory than MSG without $3 \mathrm{M}$, and rated $3 \mathrm{M}$ in water as savory. However, both of these effects were eliminated when nose-clips were used to block retronasal olfaction. 
Fig. 7 Geometric mean rated intensity ( \pm S.E.M., $Y$-axis) of various sensations for a stimulus-matrix of sucrose and 3-mercapto-2-methylpentan1-ol (3 M; $n=12)$. In some conditions subjects rated just the five basic tastes each trial, whereas in other conditions subjects rated the intensity of "onion aroma." An asterisk (*) indicates ratings significantly different from the corresponding 0 ppb $3 \mathrm{M}$ condition according to a 2-tailed Dunnet test (based on one-way ANOVAs reported in Table 2)
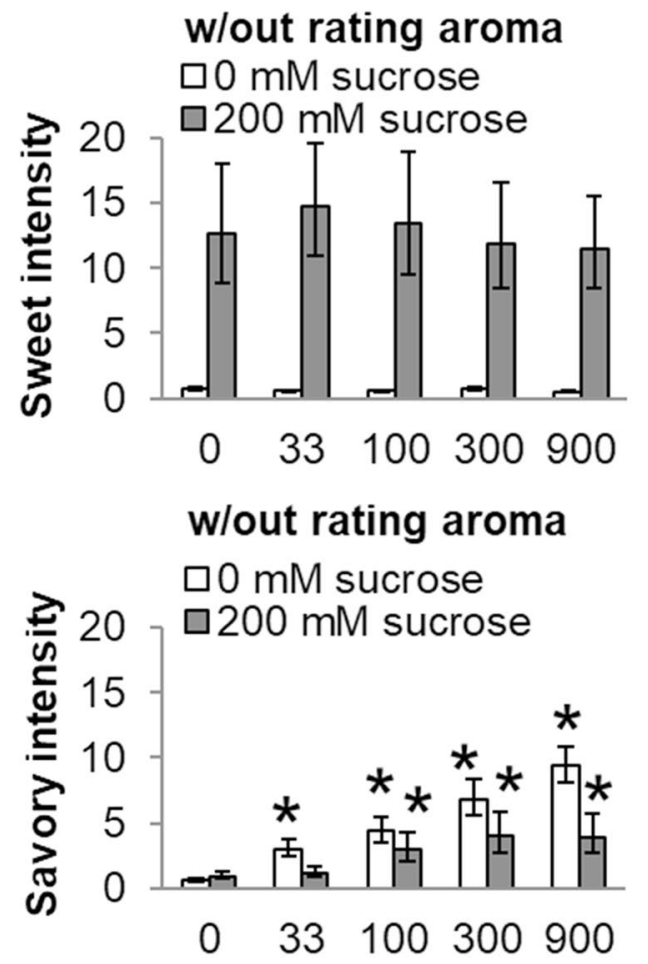

when rating aroma

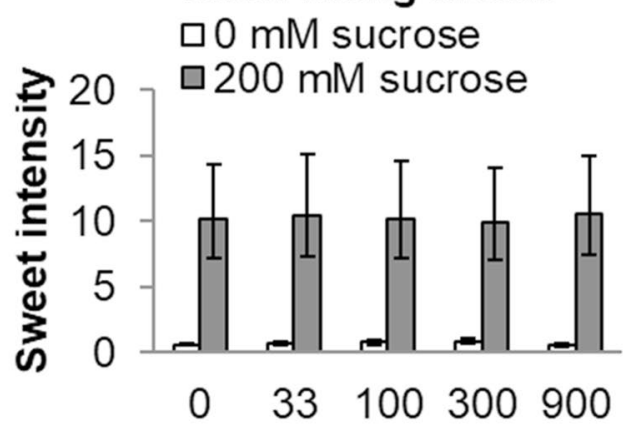

when rating aroma

$\square 0 \mathrm{mM}$ sucrose

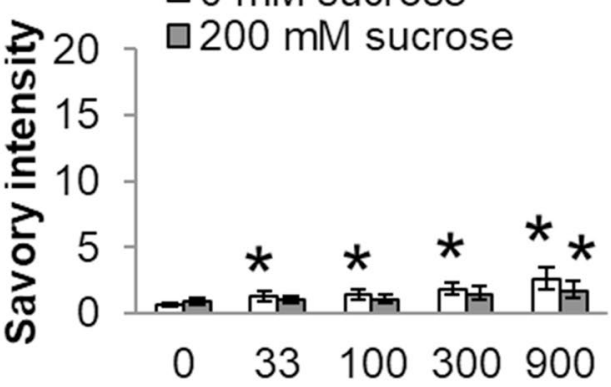

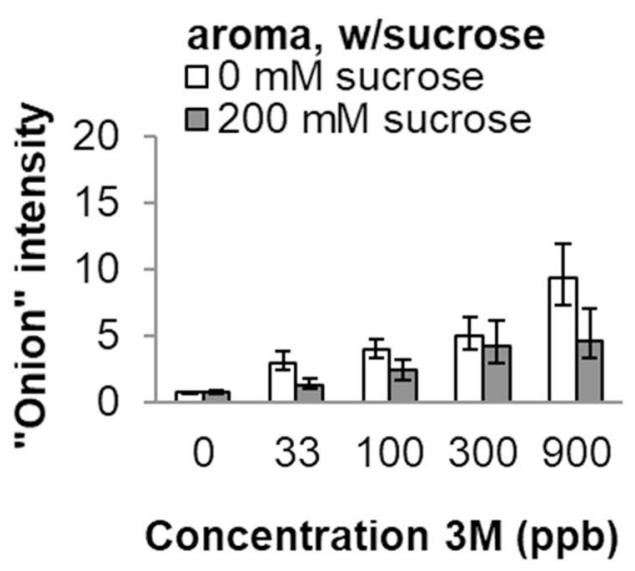

Ratings of sweetness, sourness, and bitterness were around "barely detectable" or lower, comparable to water blanks. Thus, only ratings of salty and savory intensity were analyzed further.

Salty ratings were submitted to a 3-way ANOVA: MSG (0 vs. $18 \mathrm{mM}) \times 3 \mathrm{M}(0,33,100,300$, and $900 \mathrm{ppb}) \times$ nose-clip condition (with nose-clips vs. without). The effect of MSG reached significance, $F(1,13)=22.83, p<0.001$. Samples with $18 \mathrm{mM}$ MSG were rated as somewhat salty, whereas samples without MSG were not (Fig. 8). No other effect reached significance ( $p$-values from 0.23 to 0.99 ). Thus, $3 \mathrm{M}$ had no measureable effect on the minor salty taste of MSG.

Savory ratings were submitted to a parallel 3-way ANOVA. The effect of MSG reached significance, $F(1,13)=38.20, p<0.0001$. Subjects rated $18 \mathrm{mM}$ MSG as more intensely savory than $0 \mathrm{mM} \mathrm{MSG}$ (Fig. 8). The effect of $3 \mathrm{M}$ concentration also reached significance, $F(4,52)=17.88, p<0.00001$. Savory intensity increased with $3 \mathrm{M}$ concentration, consistent with enhancement. However, there was a significant interaction between MSG concentration and $3 \mathrm{M}$ concentration, $F(4,52)=4.94, p<0.01$. As in Experiment 5, rated savory intensity increased more sharply with $3 \mathrm{M}$ concentration for samples without MSG than for samples with MSG.

The effect of nose-clips reached significance, $F(1,13)=29.57, p<0.001$. Savory ratings were higher when subjects did not wear clips. The nose-clip $\times 3 \mathrm{M}$ interaction was also significant, $F(4,52)=16.21$, $p<0.00001$. In follow-up ANOVAs, $3 \mathrm{M}$ significantly affected savory when subjects did not wear clips, $F(4,52)=28.58, p<0.00001$, but not when subjects wore clips $(p=0.87)$. A significant 3 -way interaction, 
Fig. 8 Geometric mean rated intensity ( \pm S.E.M., $Y$-axis) of savory and salty intensity for a stimulus-matrix of sucrose and 3-mercapto-2-methylpentan1-ol (3 M; $n=15)$. In some conditions subjects wore nose-clips to block retronasal olfaction, whereas in other conditions subjects did not wear clips. An asterisk (*) indicates ratings significantly different from the corresponding 0 ppb $3 \mathrm{M}$ condition according to a 2-tailed Dunnet test

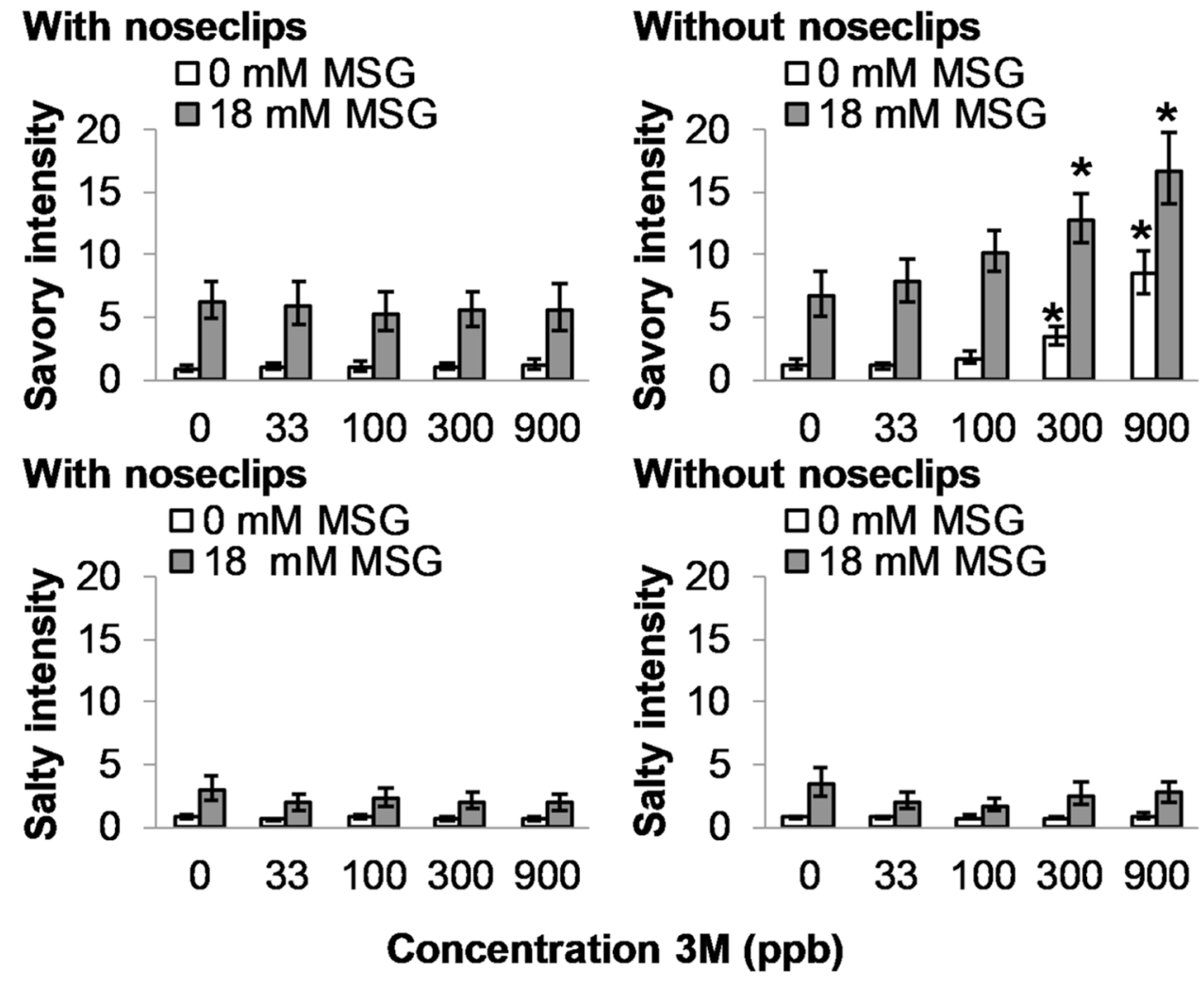

$F(4,52)=3.16, p<0.05$, reflected a significant $3 \mathrm{M} \times \mathrm{MSG}$ interaction without clips, $F(4,52)=7.29, p<0.001$, but no significant interaction with clips $(p=0.49)$. According to one-way ANOVAs, the effect of $3 \mathrm{M}$ concentration was significant for $0 \mathrm{mM}$ MSG rated without clips, $F(4,52)=27.22, p<0.00001$, and for $18 \mathrm{mM}$ MSG rated without clips, $F(4,52)=8.06, p<0.0001$. In both cases, Dunnet tests found that samples with 300 and $900 \mathrm{ppb}$ $3 \mathrm{M}$ were rated as significantly more savory than samples without $3 \mathrm{M}$. In contrast, when subjects wore nose-clips, the effect of $3 \mathrm{M}$ was not significant ( $p=0.51$ and 0.90 for 0 and $18 \mathrm{mM}$, respectively). The interaction between nose-clip condition and MSG concentration failed to reach significance $(p=0.20)$.

\section{Discussion}

\section{Detection Thresholds}

Reported ortho-nasal detection thresholds for $3 \mathrm{M}$ vary. One factor is the particular diastereoisomer (for descriptions and illustrations of the four possible isomers, see Granvogl et al. 2004). Thresholds can differ by up to 520fold or more between the least and most potent forms (Lüntzel et al. 2000; Polster and Schieberle 2017). However, even for racemic mixtures, reported thresholds vary from 0.0007 to $0.15 \mathrm{ppb}$ (Widder et al. 2000; Granvogl et al. 2004). Differences among reported odor thresholds as large as three orders of magnitude are common and have been attributed to methods (Devos 1990). Given that variation among laboratories appears to depend largely on vapor-phase stimulus control and delivery (van Harreveld et al. 1999; Cometto-Muñiz and Abraham 2010), we predict future measurements using oral presentation of liquid will be less variable. Regardless, some work suggests that concentration of volatiles in the nose may be lower for retronasal presentation (Linforth et al. 2002), consistent with reports that ortho-nasal olfaction often (though not always) tends to be more sensitive (Voiol and Daget 1986; Espinosa Diaz 2004; Heilmann and Hummel 2004; Small et al. 2005; Hummel et al. 2006). Accordingly, that our value fell closer to high end of previously reported orthonasal thresholds is perhaps unsurprising.

Regarding individual differences, the 588-fold range across our 19 participants is well within the norm for studies of ortho-nasal olfaction (reviewed in Cometto-Muñiz and Abraham 2010). In most literature on ortho-nasal sensitivity to $3 \mathrm{M}$, data on individuals are not presented or not discussed in detail. In a recent report, 100 individuals were screened for their ability to detect $3 \mathrm{M}$; with no association found between detection and single nucleotide polymorphisms in the $3 \mathrm{M}$-selective OR2M3 receptor protein (Noe et al. 2017). We found no indication of the bi- or poly-modality 
one might expect if differences are driven by SNPs in a particular receptor (Bufe et al. 2005). Though, as Noe and colleagues (Noe et al. 2017) note, minor allele frequencies for OR2M3 are low, and our sample of 19 is far too small to adequately characterize a distribution.

For oral presentation, individual differences in composition and production of saliva (including kinds or amounts of salivary enzymes), how subjects manipulate stimuli in the mouth, and general olfactory sensitivity could all contribute to observed individual differences (Burdach and Doty 1987; Mishellany-Dutour et al. 2012; Pagès-Hélary et al. 2014). For now, the only firm conclusion that we can draw, based on re-test reliability, is that individual differences appear stable over a relatively short period.

\section{Recognition Thresholds}

Mean recognition threshold $(n=18), 5.18 \mathrm{ppb}$, fell about sixfold above detection threshold. This ratio is well within the 2-tenfold range seen for olfaction in general, though higher than some reported ratios of $\sim 2$-threefold seen for many sulfur-containing compounds, including $3 \mathrm{M}$ (Hellman and Small 1974; Granvogl et al. 2004). The difference between detection and recognition could depend in part on how concentration in the nose increases with concentration in liquid, which could in turn differ between routes of presentation. However, since recognition has a subjective component in general, bias must be considered.

On average, participants responded "vanilla" or "onion" in about 37\% (combined) of trials with water blanks (Table 1). Accordingly, some subjects appeared biased toward reporting an aroma. The correlation between the ratio of recognition to detection and proportion of water blanks subjects called "onion" was non-significant but negative $(r=-0.27)$, consistent in direction with lower recognition to detection ratios for subjects more biased toward reporting "onion." Thus, bias might contribute to the larger range of individual differences (1133-fold), and relatively conservative subjects could help account for the larger number of scores distributed toward the higher end of the recognition distribution compared to detection (Fig. 2).

Potential influences of bias aside, a 1133-fold range of individual differences is not unusual for recognition of sulfur-containing compounds (Wilby 1969). Furthermore, the correlation between detection and recognition, accounting for about half the variance, suggests that both measures reflect differences in subject sensitivity, whatever the underlying mechanisms may be (though the fact that $3 \mathrm{M}$ concentrations for each participant in the recognition task were selected based on previously measured detection thresholds could also contribute to that correlation).

\section{Supra-threshold Rated Intensity}

The oral psychophysical function measured in 20 participants resembled a partial sigmoid, typical of many intensity functions for olfaction and taste (Chastrette et al. 1998; Antenucci and Hayes 2015). However, higher concentrations would be needed to clearly establish an upper asymptote, and it is not clear that odor strength would actually reach levels indicated by the function fit. In short, it would be safest to regard the reported parameters as descriptive within the range of concentrations studied. Furthermore, with oral presentation, taste or somato-sensation could influence the shape of the psychophysical function, particularly at higher concentrations. Furthermore, the concept of "onion aroma" demonstrated by $300 \mathrm{ppb} 3 \mathrm{M}$ during training might have fit perceived sensation better at some concentrations than others. Regardless, the highest concentration presented (900 ppb) was already unpleasant according to some participants (verbal report when asked), so higher concentrations are probably beyond the flavor-relevant range. To the best of our knowledge, psychophysical functions have not been reported for $3 \mathrm{M}$, for either ortho- or retronasal presentation. According to one report, a racemic mixture at $0.5 \mathrm{ppb}$ had a "...pleasant broth-like, slightly sweaty, onion-like, and leek-like..." aroma, but had a "...sulfuric, burnt gumlike, sweaty, and onion-like..." aroma at 1000 ppb (Widder et al. 2000). Many of our participants could not discriminate $0.5 \mathrm{ppb}$ from water, so again appeared less sensitive than previous ortho-nasal work might suggest. On the other hand, reports of some participants that $900 \mathrm{ppb}$ was unpleasant is consistent with past work (Widder et al. 2000).

Taken together, oral recognition and intensity measurements suggest that the prime flavor-active range for the food grade racemic mixture studied may fall between about 5 and $300 \mathrm{ppb}$. Analytic work on foods has found that $3 \mathrm{M}$ is present in raw onions and other allium varieties at about 8 to $125 \mathrm{ppb}$, in cooked allium varieties at about 35 to $367 \mathrm{ppb}$, and in vegetable and beef gravies at about 8 ppb (Granvogl et al. 2004; Christlbauer and Schieberle 2011). Accordingly, current sensitivity measures yield concentrations on the same order of magnitude as those found in ingredients, but perhaps higher than those found in at least some prepared foods. Considering our artificial method of presentation, including relatively small amounts $(2 \mathrm{ml})$, instructions to not swallow, and lack of other flavor components which could interact with $3 \mathrm{M}$, current sensitivity measures appear reasonable. Thus, current sensitivity measures can help guide initial selection of concentrations in formulation of foods and provide a foundation for further work on interactions between oral $3 \mathrm{M}$ and other flavors. That said, the reader should note that particular products might vary somewhat depending on the exact ratios of diastereoisomers present. 


\section{Experiment 4}

In Experiment 4, in which 10 participants rated the dominant taste quality of exemplars of the five basic tastes, $3 \mathrm{M}$ selectively increased the savory intensity of MSG and vanillin selectively increased the sweetness of sucrose. These results are broadly consistent with past reports of stimulus-selectivity (Frank and Byram 1988; Schifferstein and Verlegh 1996; Djordjevic et al. 2004; Isogai and Wise 2016, Wang et al. 2019), and with sweetness enhancement by "sweet" aromas like vanillin (Clark and Lawless 1994, Sakai et al. 2001; Wang et al. 2018; Bertelsen et al. 2020).

Fewer experiments have examined savory enhancement. One recent study found no impact of retronasal chicken or soy sauce aroma on the savoriness of MSG (Linscott and Lim 2016). Other studies found enhancement of savory intensity for simple solutions of MSG, for a more complex savory solution (sodium chloride, MSG, Maillard peptides, and glutathione), and for solutions of soy miso (Rolls 2000; Inoue et al. 2016; Zhou et al. 2021). Aromas that significantly enhanced savory intensity included dimethyl trisulfide, methyl furyl disulfide, 3-(methylthio)propanal, and 3-(methylthio)-1-propanol (Rolls 2000; Inoue et al. 2016; Zhou et al. 2021). All four are sulfur-containing compounds found in soy sauce or cooked soy miso, and like $3 \mathrm{M}$ have been described as having onion or garlic-like as well as meaty or broth-like notes (Rolls 2000; Inoue et al. 2016; Zhou et al. 2021). The current work adds $3 \mathrm{M}$ to this list of sulfur-containing compounds which can enhance savory taste in laboratory experiments. Taken together, the findings suggest that onion-like aromas more generally might tend to enhance savory taste, consistent with the frequent use of onions and other allium varieties in savory dishes.

Some aromas with sweet-associated notes have also been shown to enhance savory intensity, including 2,5-dimethyl4-hydroxy-3(2H)-furanone and 3-hydroxy-2-methyl-4-pyrone, both of which have salient "caramel" notes (Inoue et al. 2016; Zhou et al. 2021). Zhou and colleagues speculate that, since savory (often thought of as "delicious") and sweet are both hedonically positive, sweet-associated odorants may increase pleasantness, which could in turn increase rated savory intensity (Zhou et al. 2021). To the best of our knowledge, this hypothesis has not been tested. However, we note that vanillin, which people also tend to perceive as pleasant (Savic et al. 2002) did not affect ratings of savory taste in the current work.

Many savory dishes also taste salty as well as savory. The "savory" aroma of dried bonito flakes failed to enhance the saltiness of $\mathrm{NaCl}$ solutions when added in vapor-phase via olfactometry, but did enhance the saltiness of weak $\mathrm{NaCl}$ solutions and a reduced-sodium soup when added as a steam distillate (Manabe et al. 2014; Ogasawara et al. 2016). In other work, soy sauce aroma or aroma components significantly enhanced rated saltiness of $\mathrm{NaCl}$ solutions (Manabe et al. 2020; Zhou et al. 2021). Our modest sample size may have obscured more subtle effects on saltiness or other tastes, but under current conditions $3 \mathrm{M}$ showed the most promise as potential savory enhancer.

\section{Experiment 5}

Experiment 5 focused on $3 \mathrm{M}$-savory interactions using more complex response-contexts and multiple concentrations of $3 \mathrm{M}$ in 12 participants. Again, adding at least higher concentrations of $3 \mathrm{M}$ increased the savory intensity of MSG. However, $3 \mathrm{M}$ itself was rated as savory when no taste was present (though at least some 3 M-MSG mixtures were more savory than either MSG or $3 \mathrm{M}$ alone). $3 \mathrm{M}$ even imparted a savory note to sucrose. Flavor interactions were still selective: $3 \mathrm{M}$ did not affect the sweetness of sucrose or cooperate with sucrose in increasing savory ratings (savory was nominally weaker with sucrose). Furthermore, consistent with lack of saltiness enhancement in Experiment 4, $3 \mathrm{M}$ failed to enhance the salty minor taste of MSG.

Regardless, participants rated sensations from oral $3 \mathrm{M}$ as "savory." This result could indicate different sensory processes than taste enhancement by aromas which are perceived as tasteless when presented alone (e.g., Isogai and Wise 2016). However, sensations from retronasal odorants are often perceived as coming from the mouth, and sometimes as having taste qualities (Murphy et al. 1977; Rozin 1982; Lim and Johnson 2012; Spence 2016). For example, in one recent study participants rated lemon aroma in water as sour (Veldhuizen et al. 2017), and in two other studies subjects rated $\mathrm{NaCl}$ solutions as savory with the addition of bonito flake aroma (Manabe et al. 2014; Ogasawara et al. 2016).

Importantly, current participants reported weaker savory sensations when they rated "onion aroma" as well as taste. To the extent, sensations from oral $3 \mathrm{M}$ fit participants' concept of "savory," that concept could be narrowed to at least partially exclude sensations from oral 3 M (Frank 2003). However, even with the most complex response-context $3 \mathrm{M}$ still affected rated savory sensation. Perhaps sensations from oral $3 \mathrm{M}$ were not entirely separable from savory taste under current conditions (as discussed in Veldhuizen et al. 2017).

Regardless, concerning work on savory enhancement cited in the preceding sub-section ("Experiment 4," above) we note that the study which found no significant effect of chicken or soy sauce aroma on savory taste used a more complex response-context which might be expected to encourage a more analytic approach (Linscott and Lim 2016). In contrast, sensory judgments in the studies which found significant savory enhancement focused on savory taste alone, which might be expected to encourage a more synthetic 
approach (Rolls 2000; Inoue et al. 2016; Zhou et al. 2021). To the best of our knowledge, the current work is the first to systematically examine the effect of response-context or instructions on savory enhancement by aroma. However, taken together, current and past results suggest that savory enhancement by aroma is probably at least in part a cognitive effect and not exclusively a peripheral or receptor-level effect. That said, at least one aroma compound previously shown to enhance rated savory taste, viz., 3-(methylthio) propanal (Zhou et al. 2021), acted as a positive allosteric modulator of the human T1R1-T1R3 savory receptor protein expressed in a heterologous cell system (Toda et al. 2018). Accordingly, savory enhancement could involve multiple mechanisms, at least for some aroma compounds.

We observed no effect of taste on rated "onion aroma." Some studies have found more robust effects of taste on aroma than of aroma on taste (Green et al. 2012; Isogai and Wise 2016; Linscott and Lim 2016), though others report the opposite pattern (Veldhuizen et al. 2017). These discrepancies could depend on various methodological factors. Regardless, that ratings of onion aroma appeared lower than those measured in Experiment 3 at many concentrations is consistent with the idea that subjects attributed some amount of sensation from oral $3 \mathrm{M}$ to savory taste.

\section{Experiment 6}

Experiment 6 focused on 3 M-MSG interactions with and without nose-clips in a sample of 15 participants. Without nose-clips, results mirrored those of Experiment 5 (at least for the simpler response-context): $3 \mathrm{M}$ cooperated with MSG to increase savory intensity, $3 \mathrm{M}$ itself was rated as "savory," and $3 \mathrm{M}$ did not affect ratings of saltiness. With nose-clips (and thus, without retronasal aroma), added $3 \mathrm{M}$ had no effect on rated taste intensity. We cannot completely rule out taste or mouthfeel from oral $3 \mathrm{M}$, but the effect on savory taste in Experiments 4 and 5 would seem to depend primarily on retronasal aroma.

\section{Possible Implications for Foods}

In contrast to sweetness, savory taste (or at least the prototypical savory stimulus MSG) does not tend to be perceived as pleasant by itself, but imparts a "full, "rich," or "delicious" flavor in the context of many foods (Beauchamp 2009; McCabe and Rolls 2007; Kurihara 2015). Thus, perceptual data suggest that interactions between savory molecules like MSG and other flavor compounds in foods are crucial for consumer perception. Synergistic enhancement of the savory intensity of glutamate has been demonstrated for some non-volatile, taste-active compounds including the nucleotides 5'-Inosinate and 5'-guanylate (Kurihara 2015). Synergy between MSG and selected nucleotides is due at least in part to peripheral interactions at the T1R1-T1R3 savory receptor (Kurihara 2015). Regardless, perception of savory flavor will depend in part on the blend of taste-active molecules in foods.

However, McCabe and Rolls found that the addition of a savory-consonant vegetable aroma significantly enhanced the rated pleasantness and "fullness" of solutions of MSG mixed with inosine 5'monophosphate (MCabe and Rolls, 2007). Accompanying functional magnetic resonance imaging experiments found synergistic interactions in cortical areas believed to play a role in hedonics or reward value of foods, including orbitofrontal cortex (McCabe and Rolls 2007). The authors argued that savory flavor might be better understood as a convergence between taste and olfactory pathways in the brain than as a taste sensation (McCabe and Rolls, 2007). Aroma-enhancement of savory taste seen in current and some past work is consistent with this idea (Rolls 2000; Inoue et al. 2016; Zhou et al. 2021). Taken together, the results suggest that addition of some volatile flavor compounds might enhance perceived savory flavor, though such effects might be particular to certain food contexts. Furthermore, the results suggest that if a particular food formulation lacks the expected savory impact based on the mix of taste-active compounds present, the problem might lie in the profile of volatile compounds.

\section{Limitations}

Numbers of participants were modest, especially in Experiments 4, 5, and 6. Distributions of detection and recognition thresholds may not perfectly represent the general population. Furthermore, though savory enhancement by $3 \mathrm{M}$ was consistent, $3 \mathrm{M}$ could have more subtle effects on other rated qualities. In particular, as discussed above, savory-associated aromas have enhanced rated saltiness in other work (Manabe et al. 2014; Zhou et al. 2021). The current studies may lack sufficient power to show effects on other rated qualities. Additional studies with larger samples would be desirable.

A limitation that might affect ratings of aroma (Experiments 3 and 4) concerns possible changes in perceived quality with concentration. Participants rated "onion aroma," demonstrated using $300 \mathrm{ppb} 3 \mathrm{M}$. However, another label or combination of labels might have better described perceived aroma at $300 \mathrm{ppb}$ or other concentrations. Thus, the chosen label could have influenced the form of the intensity versus concentration function (Experiment 3 ) or how participants rated aroma in Experiment 4.

Another important limitation is that stimulus presentation was un-physiological. Though volatiles do reach the nasal cavity when subjects manipulate samples in the mouth during respiration, concentrations of retronasal aroma are particularly high after swallowing (Hodgson et al. 2005; Mishellany-Dutour et al., 2012). Participants did not swallow in the current 
experiments, so profiles of concentration reaching the nose over time probably differed substantially from those associated with natural consumption. Furthermore, samples were small in volume relative to natural sips (Lawless et al. 2003). Measured taste sensitivity tends to be higher with larger volumes, though this effect is relatively small and most pronounced at volumes substantially less than $1 \mathrm{ml}$ (O'Mahony et al. 1982; O'Mahony et al. 1984, Brosvic and McLaughlin 1989). Furthermore, reliable taste judgments are possible even with a small fraction of $1 \mathrm{ml}$ (Colvin et al. 2018; Palmer et al. 2021). However, the effect of volume on judgments of retronasal aroma have not been explored as thoroughly, so some results might differ if more natural volumes were used. Finally, the simple aqueous solutions used provide a very different and much less natural stimulus context than foods, so it is unclear how well results from the current experiments would generalize. In short, though the stimuli and procedures afforded experimental control in some respects, further experiments using more natural stimuli and sampling will be important.

\section{Conclusions}

Oral sensitivity to a food grade, racemic mixture of $3 \mathrm{M}$ was lower than past ortho-nasal studies would suggest. Whether the difference depends entirely on route of presentation is uncertain. Regardless, oral sensitivity was roughly consistent with $3 \mathrm{M}$ concentrations in ingredients and foods, so current measurements can inform starting points for formulation of foods and flavors and serve as a foundation for further flavor studies. Regarding flavor effects, $3 \mathrm{M}$ selectively enhanced savory intensity, and even seemed to impart a savory note to water. Savory enhancement was sensitive to response-context. Accordingly, whereas sensations from oral $3 \mathrm{M}$ were compatible with participants' concept of savory, $3 \mathrm{M}$ and savory were at least partially separable. Furthermore, since savory enhancement was eliminated when retronasal olfaction was blocked using nose-clips, observed taste effects depended on retronasal aroma. Together, results suggest that $3 \mathrm{M}$ is a promising candidate aroma to enhance or impart savory flavor.

Acknowledgements The study was funded by Zensho Holdings Co., Ltd and Monell institutional funds. The views expressed in this report are those of the authors and do not necessarily reflect the position or policy of the project funders.

\section{Declarations}

Conflict of interest PMW has received research funding, consulting fees, and travel re-imbursements from food, ingredient, and pharmaceutical companies, though no fees or travel expenses directly related to the topic of the paper. AL has no conflicts of interest to declare.

Ethical approval This work was performed in accordance with the ethical standards as laid down in the 1964 Declaration of Helsinki and its later amendments. Procedures were approved by an independent
Institutional Review Board at the University of Pennsylvania (protocol \#826403).

Informed consent After a consent discussion and opportunity to ask questions, participants provided written informed consent before performing any study procedures.

\section{References}

Antenucci RG, Hayes JE (2015) Nonnutritive sweeteners are not supernormal stimuli. Int J Obes 39(2):254-259

Bartoshuk LM, Duffy VB, Green BG, Hoffman HJ, Ko CW, Lucchina LA, Marks LE, Snyder DJ, Weiffenbach JM (2004) Valid across-group comparisons with labeled scales: the gLMS versus magnitude matching. Physiol Behav 82(1):109-114

Beauchamp GK (2009) Sensory and receptor responses to umami: an overview of pioneering work. Am J Clin Nutr 90(3):723S-727S. https://doi.org/10.3945/ajen.2009.27462E

Bertelsen AS, Mielby LA, Alexi N, Byrne DV, Kidmose U (2020) Individual differences in sweetness ratings and crossmodal aroma-taste interactions. Foods (Basel, Switzerland) 9(2): 146

Blankenship ML, Grigorova M, Katz DB, Maier JX (2019) Retronasal odor perception requires taste cortex, but orthonasal does not. Curr Biol 29(1):62-69.e63

Bojanowski V, Hummel T (2012) Retronasal perception of odors. Physiol Behav 107(4):484-487

Brosvic GM, McLaughlin WW (1989) Quality specific differences in human taste detection thresholds as a function of stimulus volume. Physiol Behav 45(1):15-20. https://doi.org/10.1016/ 0031-9384(89)90160-1

Bufe B, Breslin PAS, Kuhn C, Reed DR, Tharp CD, Slack JP, Kim U-K, Drayna D, Meyerhof W (2005) The molecular basis of individual differences in phenylthiocarbamide and propylthiouracil bitterness perception. Curr Biol 15(4):322-327

Burdach KJ, Doty RL (1987) The effects of mouth movements, swallowing, and spitting on retronasal odor perception. Physiol Behav 41(4):353-356

Chastrette M, Thomas-Danguin T, Rallet E (1998) Modelling the human olfactory stimulus-response function. Chem Senses 23(2):181-196

Christlbauer M, Schieberle P (2009) Characterization of the key aroma compounds in beef and pork vegetable gravies á la chef by application of the aroma extract dilution analysis. J Agric Food Chem 57(19):9114-9122

Christlbauer M, Schieberle P (2011) Evaluation of the key aroma compounds in beef and pork vegetable gravies a la chef by stable isotope dilution assays and aroma recombination experiments. J Agric Food Chem 59(24):13122-13130

Clark CC, Lawless HT (1994) Limiting response alternatives in timeintensity scaling: an examination of the halo-dumping effect. Chem Senses 19(6):583-594

Colvin JL, Pullicin AJ, Lim J (2018) Regional differences in taste responsiveness: effect of stimulus and tasting mode. Chem Senses 43(8):645-653. https://doi.org/10.1093/chemse/ bjy 055

Cometto-Muñiz JE, Abraham MH (2010) Structure-activity relationships on the odor detectability of homologous carboxylic acids by humans. Exp Brain Res 207(1-2):75-84

Delwiche J (2004) The impact of perceptual interactions on perceived flavor. Food Qual Prefer 15(2):137-146

Devos M (1990) Standardized human olfactory thresholds. IRL Press at Oxford University Press, Oxford 
Djordjevic J, Zatorre RJ, Jones-Gotman M (2004) Odor-induced changes in taste perception. Exp Brain Res 159(3):405-408

Dunnett CW (1955) A multiple comparison procedure for comparing several treatments with a control. J Am Stat Assoc 50(27):1096-1121

Espinosa Diaz M (2004) Comparison between orthonasal and retronasal flavour perception at different concentrations. Flavour Fragr J 19(6):499-504

Fan Z, Hasing T, Johnson TS, Garner DM, Schwieterman ML, Barbey CR, Colquhoun TA, Sims CA, Resende MFR, Whitaker VM (2021) Strawberry sweetness and consumer preference are enhanced by specific volatile compounds. Horticult Res 8(1):66. https://doi.org/10.1038/s41438-021-00502-5

Fan Z, Plotto A, Bai J, Whitaker VM (2021b) Volatiles influencing sensory attributes and bayesian modeling of the soluble solidssweetness relationship in strawberry. Front Plant Sci. https:// doi.org/10.3389/fpls.2021.640704

Flaherty TJ, Lim J (2017) Individual differences in retronasal odor responsiveness: Effects of aging and concurrent taste. Chemosens Percept 10(4):91-103

Fondberg R, Lundström JN, Seubert J (2021) Odor-taste interactions in food perception: exposure protocol shows no effects of associative learning. Chem Sens 46:bjab003. https://doi.org/10.1093/ chemse/bjab003.

Frank RA (2003) Response context affects judgments of flavor components in foods and beverages. Food Qual Prefer 14(2):139-145

Frank RA, Byram J (1988) Taste-smell interactions are tastant and odorant dependent. Chem Senses 13(3):445

Gadagkar SR, Call GB (2015) Computational tools for fitting the Hill equation to dose-response curves. J Pharmacol Toxicol Methods 71:68-76

Gautam SH, Verhagen JV (2010) Evidence that the sweetness of odors depends on experience in rats. Chem Senses 35(9):767-776

Granvogl M, Christlbauer M, Schieberle P (2004) Quantitation of the intense aroma compound 3-mercapto-2-methylpentan-1-ol in raw and processed onions (Allium cepa) of different origins and in other Allium varieties using a stable isotope dilution assay. J Agric Food Chem 52(10):2797-2802

Green BG (2002) Psychophysical measurement of oral chemesthesis. In: Simon SA, Nicolelis MAL (eds) Methods in Chemosensory Research. CRC Press, Boca Raton, pp 3-20

Green BG, Dalton P, Cowart B, Shaffer G, Rankin K, Higgins J (1996) Evaluating the "Labeled Magnitude Scale" for measuring sensations of taste and smell. Chem Senses 21(3):323-334

Green BG, Nachtigal D, Hammond S, Lim J (2012) Enhancement of retronasal odors by taste. Chem Senses 37(1):77-86

Hannum M, Stegman MA, Fryer JA, Simons CT (2018) Different olfactory percepts evoked by orthonasal and retronasal odorant delivery. Chem Senses 43(7):515-521

Heilmann S, Hummel T (2004) A new method for comparing orthonasal and retronasal olfaction. Behav Neurosci 118(2):412-419

Hellman TM, Small FH (1974) Characterization of the odor properties of 101 petrochemicals using sensory methods. J Air Pollut Control Assoc 24(10):979-982

Hodgson MD, Langridge JP, Linforth RS, Taylor AJ (2005) Aroma release and delivery following the consumption of beverages. $\mathrm{J}$ Agric Food Chem 53(5):1700-1706. https://doi.org/10.1021/jf040 $316 \mathrm{~g}$

Hummel T, Heilmann S, Landis BN, Reden J, Frasnelli J, Small DM, Gerber J (2006) Perceptual differences between chemical stimuli presented through the ortho- or retronasal route. Flavour Fragr J 21(1):42-47

Inoue Y, Kato S, Saikusa M, Suzuki C, Otsubo Y, Tanaka Y, Watanabe H, Hayase F (2016) Analysis of the cooked aroma and odorants that contribute to umami aftertaste of soy miso (Japanese soybean paste). Food Chem 213:521-528. https://doi.org/10.1016/j.foodc hem.2016.06.106

Isogai T, Wise PM (2016) The effects of odor quality and temporal asynchrony on modulation of taste intensity by retronasal odor. Chem Senses 41(7):557-566

Kurihara, K. (2015). Umami the fifth basic taste: history of studies on receptor mechanisms and role as a food flavor BioMed Research International 2015 (Article ID 189402). https://doi.org/10.1155/ 2015/189402

Lawless HT, Bender S, Oman C, Pelletier C (2003) Gender, age, vessel size, cup vs. straw sipping, and sequence effects on sip volume. Dysphagia 18(3):196-202. https://doi.org/10.1007/ s00455-002-0105-0

Lawrence G, Salles C, Palicki O, Septier C, Busch J, Thomas-Danguin $\mathrm{T}$ (2011) Using cross-modal interactions to counterbalance salt reduction in solid foods. Int Dairy J 21(2):103-110

Lim J, Johnson MB (2012) The role of congruency in retronasal odor referral to the mouth. Chem Senses 37(6):515-522

Linforth R, Martin F, Carey M, Davidson J, Taylor AJ (2002) Retronasal transport of aroma compounds. J Agric Food Chem 50(5):1111-1117

Linscott TD, Lim J (2016) Retronasal odor enhancement by salty and umami tastes. Food Qual Prefer 48:1-10

Lüntzel CS, Widder S, Vössing T, Pickenhagen W (2000) Enantioselective syntheses and sensory properties of the 3-mercapto-2-methylpentanols. J Agric Food Chem 48(2):424-427

Manabe M, Ishizaki S, Yamagishi U, Yoshioka T, Oginome N (2014) Retronasal odor of dried bonito stock induces umami taste and improves the palatability of saltiness. J Food Sci 79(9):S1769-1775

McCabe C, Rolls T (2007) Umami: a delicious flavor formed by convergence of taste and olfactory pathways in the human brain. Eur J Neurosci 25(6):1855-1864. https://doi.org/10.1111/j.1460-9568. 2007.05445.x

Mishellany-Dutour A, Woda A, Labouré H, Bourdiol P, Lachaze P, Guichard E, Feron G (2012) Retro-nasal aroma release Is correlated with variations in the in-mouth air cavity volume after empty deglutition. PLoS ONE 7(7):e41276. https://doi.org/10. 1371/journal.pone.0041276

Murphy C, Cain W, Bartoshuk L (1977) Mutual action of taste and olfaction. Sens Process 1(3):204-211

Manabe, M., Sakaue, R. and Obata, A. (2020), Contribution of the retronasal odor of soy sauce to salt reduction. J Food Sci, 85: 2523-2529. https://doi.org/10.1111/1750-3841.15332

Nara K, Saraiva LR, Ye X, Buck LB (2011) A large-scale analysis of odor coding in the olfactory epithelium. J Neurosci 31(25):9179-9191

Noe F, Polster J, Geithe C, Kotthoff M, Schieberle P, Krautwurst D (2017) OR2M3: a highly specific and narrowly tuned human odorant receptor for the sensitive detection of onion key food odorant 3-mercapto-2-methylpentan-1-ol. Chem Senses 42(3):195-210

Ogasawara Y, Mochimaru S, Ueda R, Ban M, Kabuto S, Abe K (2016) Preparation of an Aroma fraction from dried bonito by steam distillation and its effect on modification of salty and umami taste qualities. J Food Sci 81(2):C308-C316

O’Mahony M, Klapman K, Wong J, Atassi S (1982) Salt taste sensitivity and stimulus volume: effect of stimulus residuals. Perception 11(3):347-357. https://doi.org/10.1068/p110347

O’Mahony M, Atassi-Sheldon S, Wong J, Klapman-Baker K, Wong SY (1984) Salt taste sensitivity and stimulus volume: sips and drops some implications for the Henkin taste test. Perception 13(6):725-737. https://doi.org/10.1068/p130725

Pagès-Hélary S, Andriot I, Guichard E, Canon F (2014) Retention effect of human saliva on aroma release and respective contribution of salivary mucin and $\alpha$-amylase. Food Res Int 64:424-431 
Palmer RK, Stewart MM, Talley J (2021) Concentration-response analysis of human taste discrimination. J Pharmacol Exp Ther 377(1):133-145. https://doi.org/10.1124/jpet.120.000373

Polster J, Schieberle P (2017) Structure-odor correlations in homologous series of mercaptoalkanols. J Agric Food Chem 65(21):4329-4340

Prescott J, Stevenson R (2015) Chemosensory integration and the perception of flavor. Handbook of Olfaction and Gustation

Prescott J, Murphy S (2009) Inhibition of evaluative and perceptual odour-taste learning by attention to the stimulus elements. Q J Exp Psychol 62(11):2133-2140

Prescott J (2012) Multimodal chemosentory interactions and perception of flavor. The Neural Bases of Multisensory Processes. M. M. $\mathrm{M}$ and W. M. T. Boca Raton (FL), CRC Press/Taylor \& Francis: 703-716

Rolls ET (2000) The representation of umami taste in the taste cortex. J Nutr 130(4S Suppl):960S-965S. https://doi.org/10.1093/jn/ 130.4.960S

Roudnitzky N, Bult JH, de Wijk RA, Reden J, Schuster B, Hummel T (2011) Investigation of interactions between texture and orthoand retronasal olfactory stimuli using psychophysical and electrophysiological approaches. Behav Brain Res 216(1):109-115

Rozin P (1982) "Taste-smell confusions" and the duality of the olfactory sense. Percept Psychophys 31(4):397-401

Sakai N, Kobayakawa T, Gotow N, Saito S, Imada S (2001) Enhancement of sweetness ratings of aspartame by a vanilla odor presented either by orthonasal or retronasal routes. Percept Mot Skills 92(3 Pt 2):1002-1008

Sanganahalli BG, Baker KL, Thompson GJ, Herman P, Shepherd GM, Verhagen JV, Hyder F (2020) Orthonasal versus retronasal glomerular activity in rat olfactory bulb by fMRI. NeuroImage 212:116664

Schifferstein HN, Verlegh PW (1996) The role of congruency and pleasantness in odor-induced taste enhancement. Acta Psychol (amst) 94(1):87-105

Schwieterman ML, Colquhoun TA, Jaworski EA, Bartoshuk LM, Gilbert JL, Tieman DM, Odabasi AZ, Moskowitz HR, Folta KM, Klee HJ, Sims CA, Whitaker VM, Clark DG (2014) Strawberry flavor: diverse chemical compositions, a seasonal influence, and effects on sensory perception. PLoS One 9(2):e88446

Scott JW, Sherrill L, Jiang J, Zhao K (2014) Tuning to odor solubility and sorption pattern in olfactory epithelial responses. J Neurosci 34(6):2025-2036

Shepherd GM (2006) Smell images and the flavour system in the human brain. Nature 444(7117):316-321

Small DM, Gerber JC, Mak YE, Hummel T (2005) Differential neural responses evoked by orthonasal versus retronasal odorant perception in humans. Neuron 47(4):593-605

Spence C (2016) Oral referral: on the mislocalization of odours to the mouth. Food Qual Prefer 50:117-128

Spence C (2021) What Is the relationship between the presence of volatile organic compounds in food and drink products and multisensory flavour perception? Foods 10(7):1570. https://doi. org/10.3390/foods 10071570

Stevenson RJ, Prescott J, Boakes RA (1995) The acquisition of taste properties by odors. Learn Motiv 26(4):433-455

Tieman D, Bliss P, McIntyre LM, Blandon-Ubeda A, Bies D, Odabasi AZ, Rodríguez GR, van der Knaap E, Taylor MG, Goulet C, Mageroy MH, Snyder DJ, Colquhoun T, Moskowitz H, Clark DG, Sims C, Bartoshuk L, Klee HJ (2012) The chemical interactions underlying tomato flavor preferences. Curr Biol 22(11):1035-1039

Toda Y, Nakagita T, Hirokawa T, Yamashita Y, Nakajima A, Narukawa M, Ishimaru Y, Uchida R, Misaka T (2018) Positive/negative allosteric modulation switching in an umami taste receptor (T1R1/T1R3) by a natural flavor compound, methional. Sci Rep 8:1-13. https://doi.org/10.1038/s41598-018-30315-x

van der Klaauw NJ, Frank RA (1996) Scaling component intensities of complex stimuli: The influence of response alternatives. Environ Int 22(1):21-31

van Harreveld AP, Heeres P, Harssema H (1999) A review of 20 years of standardization of odor concentration measurement by dynamic olfactometry in Europe. J Air Waste Manag Assoc 49(6):705-715

Veldhuizen MG, Siddique A, Rosenthal S, Marks LE (2017) Interactions of lemon, sucrose and citric acid in enhancing citrus, sweet and sour flavors. Chem Senses 43(1):17-26

Voiol E, Daget N (1986) Comparative study of nasal and retronasal olfactory perception. Food Sci Technol 19(4):316-319

Wang QJ, Mielby LA, Junge JY, Bertelsen AS, Kidmose U, Spence C, Byrne DV (2019) The role of intrinsic and extrinsic sensory factors in sweetness perception of food and beverages: a review. Foods 8(6)

Wang, G., E. J. Hayes, R. G. Ziegler, F. R. Roberts and H. Hopfer (2018). Dose-response relationships for vanilla flavor and sucrose in skim milk: evidence of synergy. Beverages 4(4).

Wetherill GB, Levitt H (1965) Sequention estimation of points on a psychometric function. Br J Math Stat Psychol 18(1):1-10

Widder S, Sabater Lüntzel C, Dittner T, Pickenhagen W (2000) 3-Mercapto-2-methylpentan-1-ol, a new powerful aroma compound. J Agric Food Chem 48(2):418-423

Wilby FV (1969) Variation in recognition odor threshold of a panel. J Air Pollut Control Assoc 19(2):96-100

Wise PM, Breslin PA (2013) Individual differences in sour and salt sensitivity: detection and quality recognition thresholds for citric acid and sodium chloride. Chem Senses 38(4):333-342

Zhou T, Feng Y, Thomas-Danguin T, Zhao M (2021) Enhancement of saltiness perception by odorants selected from Chinese soy sauce: a gas chromatography/olfactometry-associated taste study. Food Chem 335:127664. https://doi.org/10.1016/j.foodchem.2020. 127664

Publisher's Note Springer Nature remains neutral with regard to jurisdictional claims in published maps and institutional affiliations. 